\title{
AWARENESS OF GLAUCOMA AND EYE HEALTH SERVICES AMONG FAITH-BASED COMMUNITIES IN KUMASI, GHANA
}

Calum Murdoch ${ }^{1 *}$, BSc

Kennedy Opoku², Dip Ophthalmology, MSc Ian Murdoch ${ }^{3}$, MD, FRCOphth, FWACS

${ }^{1}$ Leeds Institute of Health Sciences, University of Leeds, 101 Clarendon Road, Leeds, LS2 9LJ, UK

${ }^{2}$ Agogo Presbyterian Hospital, Eye Unit, PO box 27, Agogo, AsanteAkyem, Ghana

3 Institute of Ophthalmology, University College London, 11-43

Bath Street, London, EC1V 9EL, UK

*Corresponding Author

Email: um11clm@leeds.ac.uk

Phone: +447951341625

Funding: None

Competing interests: None declared 


\begin{abstract}
Purpose

To determine awareness of glaucoma, 'hinta anifraye' and available eye health services among urban communities in Kumasi, Ghana. 'Hinta anifraye' is a recently developed term for glaucoma in the local Twi language.
\end{abstract}

\title{
Methods
}

Convenience sampling was used to survey the communities of four churches and two mosques in Kumasi, recruiting participants as they arrived to attend religious services. Ten interviewers collected data via quantitative, intervieweradministered questionnaires. An awareness grading system was devised to categorise participant knowledge from Level 0-4.

\section{Results}

Of a total 484 respondents, 269 (56\% [95CI 52-60\%]) had heard of glaucoma, and 284 (60\% [95CI 56-64\%]) had heard of either glaucoma or hinta anifraye. Only 142 (29\%) had disease-specific knowledge of symptoms or causes. TV and radio were the main reported sources of information. Education, religious community, English language, male sex and older age were all found to be significant indicators of awareness, with education shown to be a key confounding factor. Overall 436 (90\%) mentioned either a hospital or doctor as a place they knew they could seek help for an eye problem. 


\section{Conclusions}

Awareness of glaucoma is higher than previously suggested from similar studies, but still very low from a global perspective. The findings suggest that media is a useful tool in disseminating health messages. Awareness of professional care was found to be remarkably high. Eye health promotion is recommended to raise awareness of glaucoma among this population. 


\section{Awareness of glaucoma and eye health services among faith-based communities in Kumasi, Ghana}

\section{INTRODUCTION}

Globally, glaucoma is the second leading cause of blindness after cataract ${ }^{(1,2)}$ and the primary cause of irreversible blindness(3). Glaucoma has higher prevalence amongst people of African descent, as well as earlier onset and more rapid progression, than in those of European descent(2-6). Furthermore, evidence suggests that West Africa bears a heavier burden of glaucoma than other African regions $(4,6,7)$. Prevalence in Ghana is particularly high(4,8,9), especially in relation to findings from Eastern or South Africa(4).

Public awareness of glaucoma in West Africa is reportedly low(4,10-13), with those having heard of the disease ranging from $3.6 \%$ in Ghana to $47 \%$ in Nigeria(10,13). Other studies among West African students, health workers and eye clinic attendees have found higher numbers having heard of glaucoma but few with actual knowledge about the disease(14-18). Consequently, West Africa has a large unmet need for glaucoma health promotion ${ }^{(9,10,12,16,19)}$.

To date, few studies have focused directly on glaucoma awareness in Ghana(11,13,18). This study aimed to investigate awareness of glaucoma among members of faith-based communities in Kumasi, Ghana's second largest city ${ }^{(20) .}$ Such places of worship are a useful way to access the population $(21,22)$, particularly since Ghana's population comprises 71\% Christian and 18\% Muslim(20). 
Public awareness of 'hinta anifraye' was also investigated, a new word for glaucoma in the local dialect of Akan (Twi). The word has been piloted as part of a successful health campaign(11) and subsequently adopted by The Glaucoma Association of Ghana(23).

A secondary aim of the study was to investigate public awareness of available eye health services, which has shown to affect service uptake (and thus treatment) for other cause of blindness in West Africa 24,25$)$.

Such information may prove particularly useful in the planning of future health interventions. The study subsequently aims to provide baseline data for a glaucoma health intervention in the region. 


\section{MATERIALS AND METHODS}

A team of ten interviewers collected data using a structured questionnaire. Four churches and two mosques were each visited once, on separate days over a period of two weeks in May 2015. Convenience sampling was used to recruit members as they attended a religious service at each place of worship.

The churches and mosques were selected based upon proximity, accessibility and size, and were not therefore a randomised cross-section of the urban population. Risk of repeat interview of the same participant was considered small since each community was only visited once, the churches were of different denominations, and no rewards were offered for participation.

Nine student volunteer interviewers were recruited from a local teaching hospital and were provided a training day by the principal investigator to ensure consistency in interview technique. All were literate, fluent in both English and Twi, and reported to be confident in verbally translating written English to Twi.

In total, eight interviewers spoke both English and Twi, one spoke just English, and one spoke English, Twi and Hausa. Participant inclusion criteria were those aged 18 or over, with capacity to consent and ability to communicate in interview. Interviewers were instructed to approach participants from a wide range of demographics (for example both males and females, old and young), to create a purposive element to the sampling with the aim of minimising selection bias. Informed consent was obtained verbally and a research information sheet provided with each interview. 
Previous studies on glaucoma awareness were used to guide questionnaire design, including order of questions and selection of particular participant demographics(11,13,26). Only participants claiming to have heard of either glaucoma or hinta anifraye were asked further questions on disease knowledge. These questions included where they first heard the name, how much they believed they knew (just the name, a little, or a lot), and if they knew of any symptoms or causes of the disease. Participants claiming to only know the name of the disease were not asked further questions on symptoms and causes.

All participants, regardless of glaucoma knowledge, were then asked to name all the places they knew could provide help for their eyes, if they would seek help for an eye problem, and if so where they would first seek help.

Responses were partially pre-coded to facilitate interview efficiency and analysis. The questionnaire was piloted outside Kumasi and subsequent adjustments made to ensure clarity of wording and appropriate question order.

\section{Ethics}

Ethical approval for the study was granted by the Leeds Institute of Health Sciences Research Ethics Sub-Committee.

\section{Analysis}

All data was anonymised, entered electronically and analysed using contingency tables and logistic regression with STATA (v7)(27). 
A knowledge scale was created for those who had heard of glaucoma/hinta anifraye. For responses concerning symptoms of glaucoma, a score of 0 was awarded for no knowledge or incorrect knowledge. A score of 1 represented knowledge that symptoms relate to the eye and a score of 2 represented accurate knowledge of disease-specific symptoms. This was used again for responses concerning causes of glaucoma, and the two scores were summated. Thus a knowledge grade of 0-4 was possible by the sum of scores for symptoms and causes. An overall score of 0 denoted no correct knowledge of either symptoms or causes of glaucoma; a score of 4 denoted accurate disease-specific knowledge for at least one symptom and at least one cause.

\section{RESULTS}

A total of 484 questionnaires were collected from eligible respondents. Participant demographic data is summarised in Table 1. 


\section{Awareness and Knowledge}

Participant awareness and knowledge of glaucoma is summarised in Table 2. 284 (60\%, [95CI 56-64\%]) respondents reported to have heard of either glaucoma or the new term hinta anifraye. 269 (56\% [95CI 52-60\%]) had heard of glaucoma whereas only 85 (18\% [95CI 15-21\%]) had heard of hinta anifraye. A total of 142 (29\% [95CI 25-33\%]) participants demonstrated disease-specific knowledge concerning symptoms or causes of glaucoma. Knowledge here is defined as correctly identifying at least one disease-specific symptom or cause.

Of those aware, a majority (164/263 [62\%, 95CI 56-68\%]), had first heard of the disease via TV or radio. 
Logistic regression was undertaken for factors associated with awareness of either glaucoma and/or hinta anifraye. The dataset was then restricted to those reporting awareness and logistic regression undertaken for knowledge of glaucoma grade 0-4 (as outlined above), displayed in Table 3.

The results from univariate analysis show that both awareness and knowledge of glaucoma were significantly higher in males, church community, those able to speak English and the more educated. Awareness was also higher in those in formal employment. However, multivariate analysis reveals considerable confounding by education. Sex, community and occupation were no longer significant, whilst ability to speak English remained significant only for disease awareness (not knowledge). Education was the principal explanatory factor.

Older age was found insignificant in univariate analysis, but highly significant for both awareness and knowledge in multivariate analysis.

No relationship was found between self-reported knowledge (claiming to know a lot/a little about glaucoma) and level 0-4 knowledge score. 


\section{Awareness of Eye Health Services}

462/484 (95\%) participants reported that they would seek help if they had an eye problem. Of the 449 who gave a response indicating where they would first seek help the vast majority, 411 (92\%), would go to a hospital or doctor, $19(4 \%)$ would go to an optometrist and $6(1 \%)$ to a pharmacist. The remaining $13(3 \%)$ had mainly faith based responses with one seeking help outside the country, another advocating self-therapy and one looking to family.

Overall, regardless of first preference, $436(90 \%)$ mentioned either a hospital or doctor as a place they knew they could seek help for an eye problem.

\section{DISCUSSION}

The $56 \%$ (95CI 52-60\%) of respondents claiming to have heard of glaucoma is slightly higher than in other studies among the West African general public(10-13), ranging from $3.6 \%$ to $47 \%(10,13)$. One explanation for this may be that several of these studies focused on rural populations, with the exception of one other urban study in Togo reporting 30\% awareness ${ }^{(12)}$. Conversely, the proportion is lower than findings among West African health science students, health workers and eye clinic attendees(14,15,17,18), whose awareness ranged from 69 - 100\%. This is not surprising given the inherent bias of these populations.

Similar comparisons can be made for glaucoma knowledge. The current study found $29 \%$ could correctly identify symptoms or causes, compared to $0 \%-3.6 \%$ seen elsewhere among the Ghanaian public ${ }^{(11,13)}$. Again, this may be explained by urban-rural differences; a study in urban Togo found a slightly higher $9.2 \%$ public knowledge of the disease's relation to blindness(12). 
Knowledge of glaucoma in our study may be a conservative estimate since participants claiming to 'only know the name' of glaucoma were not asked further questions about signs and symptoms. These questions may have revealed additional knowledge in some cases.

In a global context, the proportion of the public aware of glaucoma is midway between findings from other developing countries $\left(2.3 \%-13.5 \%\right.$ in India $\left.{ }^{(28,29)}\right)$ and developed countries (73\%-78.4\% in the UK, China, Germany and U.S.(26,30-32). This reflects Ghana's middle socio-economic status(33), and implies that awareness, although imperfect, is not as low as previously thought $(4,11,13)$.

Education and occupation have both been widely reported as indicators of glaucoma awareness $(10,13,16,26,28-30,32,34)$. Our findings suggest that education is the strongest explanatory variable. The relationship suggests a greater need for health promotion among the less educated in Ghana.

Several studies report significant associations between age and sex with glaucoma awareness. However, findings differ on whether awareness is higher in males or females(16,28,30), or increases with age $(10,26,30)$. Moreover, several other publications have shown no association(18,32,34). Our study found higher awareness and knowledge among males and older age groups; the trend seen among males was largely due to confounding by education.

Ability to speak English was reported to be a significant indicator for glaucoma awareness in a U.S. study(32). The strong associations also found in this study had 
a confounding influence from education, confirming the known connection between English language and education in Africa(35). The findings may support the argument for using local language to facilitate health promotion ${ }^{(11)}$. In this way health messages may better reach underserved, less educated populations(35).

TV and Radio were found to be the main sources of glaucoma knowledge, consistent with findings from other West African studies(13,18). Research further afield, however, reports friends and family to be the principal source of information(29,31,34). In this study, friends and family were reported as the first source of information by $19 \%$, after TV (33\%) and Radio (29\%). It is important to note the questionnaire only asked where participants first heard of the disease; respondents may have provided more than one place if given the option. Nonetheless, such information shows the power of media in conveying health messages. These media channels may be further utilised in future health promotion.

Awareness of eye services has been described as a key barrier to health service uptake in West Africa(24,25,36), and is reported to be generally low(36,37). In contrast, the findings from this study show an exceptionally high awareness, particularly for doctor or hospital services (90\%). Similarly, the findings in an urban population in Lome also revealed a majority awareness(12). This may suggest a rural/urban divide.

However, there are two key limitations that should be considered with these results: 
- In some cases, participants reported they would visit the 'eye clinic.'

There was ambiguity here in whether they meant doctor or optometrist. Thus, awareness of optometry services may be somewhat underreported.

- The questionnaire did not test for knowledge of specific screening or treatments. Judging by the general lack of disease knowledge (29\%), a more detailed survey may have teased out true awareness of specific services (e.g. glaucoma screening).

Regardless, most participants reported they would consult professional help for an eye problem, indicating positive health-seeking behaviour. Further study is required to determine if this reflects actual health-seeking behaviour(38).

A final two limitations are the use of interviewer translation at the time of delivery of the questionnaire, and the convenience sampling methods. Participants who spoke neither English, Twi nor Hausa had to be excluded due to language barriers, thus limiting our inclusion capacity. Furthermore, Twi is not commonly used in written form and no written record was made in this language. Use of a predetermined script would have reduced potential bias in delivery. The training day and continuous monitoring of data collection, (and retraining when required), attempted to minimise this potential source of bias. Finally, a truly random participant and church/mosque selection method would have yielded a more strictly representative population sample. Such randomisation of either religious communities or people within them was not possible given logistic and resource constraints. The study was not a crosssection of the whole urban population and findings can therefore only be applied 
locally. The purposive approach applied to the convenience sampling method within our selected population attempted to reduce the probability of potential selection bias.

\section{Conclusions}

Awareness of glaucoma was found to be higher in this population than previously indicated for the West African general public. This difference may relate to the study of an urban rather than a rural population. However, the proportion still compares unfavourably to findings from more developed countries. Correct knowledge of the disease is poor, at 29\%. This implies a need for glaucoma health promotion, as has been previously advocated. Education, religious community, English language, male sex and older age were all found to be significant indicators of awareness, with education shown to be a key confounding factor. TV and radio were reported as the principal sources of information. This would imply they should be considered in future health promotion. Awareness of eye services was high, with excellent awareness of the existence of professional help.

This research serves to shed further light on a field of international medicine where the population have high burden of disease and a real health need(5,8,9,19). The findings will be used as baseline data for a glaucoma health intervention in the region. 


\section{Acknowledgements}

We wish to warmly thank Godfred Adjei Bonsu, David Antwi, Mantani Nuhu Samad, Mahmoud Mohammed-Rabiu, Stephanie Ofori Amanfo, Eunice Osei Konadu, Beatrice Serwaa Frimpong, Emmanuel Larbie Adjetey, Daniel Addai Yeboah and Noah Bortei Borketey-La for their diligent hard work and invaluable contributions as volunteer interviewers, Helen Baker for her recommendations as a social scientist, and Comfort Mshelia for her considered guidance in the planning stages of this research.

We also wish to thank the mosque and church leaders for their kind permission to conduct this research and all interviewees for their participation.

Funding: None

Competing interests: None declared

Ethical approval: Granted by the Leeds Institute of Health Sciences Research Ethics Sub-Committee 


\section{References}

1. WHO. Global Data on Visual Impairments 2010. [Internet]. Geneva, Switzerland: WHO; 2012. [Cited 2015 Jul]. Available from: http://www.who.int/blindness/GLOBALDATAFINALforweb.pdf

2. Quigley HA, Broman AT. The number of people with glaucoma worldwide in 2010 and 2020. British Journal of Ophthalmology. 2006 Mar;90(3):2627.

3. Tham YC, Li X, Wong TY, et al. Global prevalence of glaucoma and projections of glaucoma burden through 2040: a systematic review and meta-analysis. Ophthalmology. 2014 Nov;121(11):2081-90.

4. Budenz DL, Barton K, Whiteside-de Vos J, et al. Prevalence of glaucoma in an urban West African population: The Tema Eye Survey. JAMA Ophthalmology. 2013 May;131(5):651-8.

5. Kyari F, Abdull MM, Bastawrous A, et al. Epidemiology of glaucoma in subsaharan Africa: prevalence, incidence and risk factors. Middle East African Journal of Ophthalmology. 2013 Apr-Jun;20(2):111-25.

6. Budenz DL, Singh K. Glaucoma Care in West Africa. Journal of Glaucoma. 2001 Aug;10(4):348-53.

7. Cook C. Glaucoma in Africa: size of the problem and possible solutions. Journal of Glaucoma. 2009 Feb;18(2):124-8.

8. Ntim-Amponsah CT, Amoaku WM, Ofosu-Amaah S, et al. Prevalence of glaucoma in an African population. Eye (Lond). 2004 May;18(5):491-7.

9. Otabil KB, Tenkorang SB, Mac AL, et al. Prevalence of Glaucoma In An Eye Clinic In Ghana. Russian Open Medical Journal. 2013;2(3):0310. 
10. Durowade KA, Salaudeen AG, Musa OI, et al. Knowledge and Risk Factors for Glaucoma among Adults in a Rural Community of Kwara State, NorthCentral Nigeria. TAF Prev Med Bull. 2014;13(5):375-80.

11. Opoku K, Murdoch IE. Bridging the language barrier in health awareness. JAMA Ophthalmology. 2013 Oct;131(10):1367.

12. Balo PK, Serouis G, Banla M, et al. Knowledge, attitudes and practices regarding glaucoma in the urban and suburban population of Lomé (Togo). Sante. 2004 Jul-Sep;14(3):187-91.

13. Ntim-Amponsah CT, Winfried MKA, Ofosu-Amaah S. Awareness and knowledge of Glaucoma and other diseases associated with blindness in a Ghanaian community. Nigerian Journal of Ophthalmology. 2004;12(2):504.

14. Onabolu 00, Bodunde OT. Awareness and knowledge of glaucoma among primary care givers in a developing country. Annals of Tropical Medicine and Public Health. 2014;7(1):5-8.

15. Komolafe OO, Omolase CO, Bekibele CO, et al. Awareness and knowledge of glaucoma among workers in a Nigerian tertiary health care institution. Middle East African Journal of Ophthalmology. 2013 Apr-Jun;20(2):163-7.

16. Adegbehingbe BO, Bisiriyu LA. Knowledge, attitudes, and self care practices associated with glaucoma among hospital workers in Ile-Ife, Osun State, Nigeria. Tanzania Journal of Health Research. 2008 Oct;10(4):240-5.

17. Onunkwor C, Monareng LV. Glaucoma Knowledge of Patients in Abuja, Nigeria. Africa Journal of Nursing and Midwifery. 2012;14(1):3-15. 
18. Boadi-Kusi SB, Kyei S, Mashige KP, et al. Awareness, knowledge and selfcare practices toward glaucoma among final year health science university students in Ghana. Clinical and Experimental Optometry. 2015 Mar;98(2):160-7.

19. Lawrence SD, Budenz DL. Meeting the Challenge of Glaucoma in Africa. Glaucoma Today. [Internet]. 2013 Jul-Aug [cited 2015 Jul]:18-20. Available from: http://glaucomatoday.com/pdfs/gt0713 international;.pdf

20. The World Factbook: Ghana [Internet]. Central Intelligence Agency [updated 2015 Nov 19; cited 2015 Nov 23]. Available from: https://www.cia.gov/library/publications/the-worldfactbook/geos/gh.html

21. Campbell MK, Hudson MA, Resnicow K, et al. Church-based health promotion interventions: evidence and lessons learned. Annual Review of Public Health. 2007;28:213-34.

22. DeHaven MJ, Hunter IB, Wilder L, et al. Health programs in faith-based organizations: are they effective? American Journal of Public Health. 2004 Jun;94(6):1030-6.

23. Okertchiri JA, Dzidzornu, A. 'Don't Tax Glaucoma Drugs'. Daily Guide. [Internet]. 2015 Mar 11 [cited 2015 Jul]. Available from: http://www.dailyguideghana.com/dont-tax-glaucoma-drugs/

24. Ukponmwan CU, Afekhide OE, Uhunmwangho OM. Reducing the barriers to the uptake of cataract surgical services in a tertiary hospital. Orient Journal of Medicine. 2010;22(1-4). 
25. Ayanniyi AA, Bob-Egbe S, Olatunji FO, et al. Social marketing potential of qualitative cost-free-to-patient eye care program in a Nigerian community. Annals of African Medicine. 2009 Oct-Dec;8(4):225-8.

26. Baker H, Cousens SN, Murdoch IE. Poor public health knowledge about glaucoma: fact or fiction? Eye (Lond). 2010 Apr;24(4):653-657.

27. StataCorp. Stata Statistical Software: Release 7. College Station, TX: StataCorp LP; 2001.

28. Sathyamangalam RV, Paul PG, George R, et al. Determinants of glaucoma awareness and knowledge in urban Chennai. Indian Journal of Ophthalmology. 2009 Sep-Oct;57(5):355-60.

29. Dandona R, Dandona L, John RK, et al. Awareness of eye diseases in an urban population in southern India. Bulletin of the World Health Organisation. 2001;79(2):96-102.

30. Lau JT, Lee V, Fan D, et al. Knowledge about cataract, glaucoma, and age related macular degeneration in the Hong Kong Chinese population. British Journal of Ophthalmology. 2002 Oct;86(10):1080-4.

31. Pfeiffer N, Krieglstein GK, Wellek S. Knowledge about glaucoma in the unselected population: A German survey. Journal of Glaucoma. 2002 Oct;11(5):458-63.

32. Altangerel U, Nallamshetty HS, Uhler T, et al. Knowledge about glaucoma and barriers to follow-up care in a community glaucoma screening program. Canadian Journal of Ophthalmology. 2009 Feb;44(1):66-9.

33. World Bank: Ghana [Internet]. The World Bank. [updated 2015 Nov; cited 2015 Nov 23]. Available from:

http://www.worldbank.org/en/country/ghana 
34. Tenkir A, Solomon B, Deribew A. Glaucoma awareness among people attending ophthalmic outreach services in Southwestern Ethiopia. BMC Ophthalmology. 2010 May 28;10:17.

35. Alidou H, Brock-Utne B, Diallo YS, et al. Optimising Learning, Education and Publishing in Africa: The Language Factor. [Internet]. Germany: UIL/ADEA; 2011. [Cited 2015 Jul]. Available from: http://unesdoc.unesco.org/images/0021/002126/212602e.pdf

36. Lewallen S, Courtright P. Blindness in Africa: present situation and future needs. British Journal of Ophthalmology. 2001 Aug;85(8):897-903.

37. Owoeye JFA, Ademola-Popoola DS, Adekoya BJ, et al. A study of the level of awareness, of different cadre of eye care providers, among tertiary institution students in Nigeria. Annals of Biomedical Sciences. 2013 Jan;12(1):76-83.

38. Hausmann-Muela S, Ribera JM, Nyamongo I. DCPP Working Paper No. 14, Health-seeking behaviour and the health system response. [Internet]. 2003 Aug. [Cited 2015 Jul]. Available from: http://passinternational.org/site/images/stories/publications/DCPP Working Pape $\underline{\text { r } 14 \text { No Health seeking behaviour and the health system response.pdf }}$ 